\title{
Evaluating the impact of a quality of life assessment with feedback to clinicians in patients with schizophrenia: randomised controlled trial
}

Laurent Boyer, Christophe Lançon, Karine Baumstarck, Nathalie Parola, Julie Berbis and Pascal Auquier

\section{Background}

Quality of life (QoL) measurements are increasingly considered to be an important evaluation of the treatment and care provided to patients with schizophrenia. However, there is little evidence that assessing QoL improves patient outcomes in clinical practice.

\section{Aims}

To investigate the impact of a QoL assessment with feedback for clinicians regarding satisfaction and other health outcomes in patients with schizophrenia.

\section{Method}

We conducted a 6-month, prospective, randomised and controlled open-label study. Patients with schizophrenia were assigned to one of three groups: standard psychiatric assessment; QoL assessment with standard psychiatric assessment; and QoL feedback with standard psychiatric assessment. The primary outcome was patient satisfaction at 6 months. The local ethics committee (Comité de Protection des Personnes Sud-Méditerranéee $V$, France, trial number 07 067) and the French drug and device regulation agency (Agence Française de Sécurité Sanitaire des Produits de Santé, France, trial number A01033-50) approved this study.

\section{Results}

We randomly assigned 124 patients into groups. Quality of life feedback significantly affected patient satisfaction. Global satisfaction was significantly higher in the QoL feedback group $(72.5 \%$ of patients had a high level of satisfaction) compared with the standard psychiatric assessment (67.5\%) and QoL assessment groups (45.2\%). Despite trends towards decreased severity for all clinical outcomes and increased changes to medication in the QoL feedback group at 6-month follow-up, these effects were not significant.

\section{Conclusions}

Quality of life feedback positively influences patient satisfaction, which confirms the relevance of measuring QoL in clinical practice. The absence of a significant effect of QoL feedback on clinical outcomes also suggests that clinicians did not use these data optimally. Our findings suggest a nocebo effect of QoL assessment without feedback that should be considered by researchers and clinicians.

\section{Declaration of interest}

None.
Regulatory agencies such as the National Cancer Institute and the National Authority for Health in France recommend assessing quality of life (QoL) in daily clinical practice in patients with chronic illnesses. In particular, QoL measurements are increasingly considered to be an important way of evaluating the treatments and care provided to patients with schizophrenia. ${ }^{1,2}$ Using QoL measures may provide clinicians with information regarding the general health statuses of their patients that might otherwise go unrecognised, ${ }^{3,4}$ thereby improving patient satisfaction and health outcomes. ${ }^{5}$ Thus, clinicians should consider QoL measures in the same way as routine objective measures such as symptomatic evaluation scales, laboratory tests and radiographs to manage the care of patients. ${ }^{6}$

Despite the acknowledged need to consider QoL issues in clinical practice, its measurement has not been routinely implemented, ${ }^{7}$ especially in psychiatry. ${ }^{5,89}$ Practical and attitudinal barriers have been described. ${ }^{10}$ Obtaining QoL data in an efficient real-time manner is difficult because of feasibility issues (i.e. the lack of computer stations, hand-held devices $\left.{ }^{6}\right)$. Moreover, physicians often overlook QoL assessment as a result of time pressures and clinical constraints as well as a lack of training and interest. ${ }^{11}$ Therefore, more work must be undertaken to increase the use of QoL instruments in clinical practice. In particular, trials are necessary to build a satisfactory evidence base for the routine clinical use of QoL in psychiatry ${ }^{12,13}$ as has already been accomplished in oncology. ${ }^{14-17}$ To our knowledge, and based on an extensive review, ${ }^{18}$ only one previous randomised study in mental health has reported on the effectiveness of feedback of a standardised outcome assessment including QoL. ${ }^{19}$ This found no difference in the mean follow-up QoL between a treatment as usual group and a feedback group. However, the specifics of this study should be mentioned: it was performed on a heterogeneous sample with different mental health illnesses and a short follow-up time. Moreover, it lacked a third control group, including assessment without feedback, that allowed for the isolation of the effect of a single assessment. These limitations prompted us to design a prospective and randomised trial to investigate the impact of QoL assessment with feedback for clinicians regarding satisfaction and other health outcomes in patients with schizophrenia.

\section{Method}

\section{Study site and patient eligibility}

This study was conducted at the Sainte-Marguerite University Hospital, a specialised psychiatric treatment centre in Marseille, France. The sample consisted of patients who attended the day hospital over a 6-month period. All consecutive attendees who came to the day hospital were approached to participate. The inclusion criteria were: age over 18 years, diagnosis of schizophrenia according to the DSM-IV-TR criteria, ${ }^{20}$ stable 
disease status (no need for a hospital admission at inclusion and no major change in patient condition for 2 months prior to inclusion) and native French speaking. The exclusion criteria were: reduced capacity to consent, ${ }^{21}$ an Axis I diagnosis on the DSM-IV other than schizophrenia, acute decompensation of organic disease or mental retardation. The patients were provided with both oral and written information regarding the study prior to obtaining their informed consent. The local ethics committee (Comité de Protection des Personnes Sud-Méditerranée V, France, trial number 07 067) and the French drug and device regulation agency (Agence Française de Sécurité Sanitaire des Produits de Santé, France, trial number A01033-50) approved this study.

\section{Design}

The present study was a 6-month, prospective, randomised, controlled, open-label and single-centre study. Figure 1 displays a flow chart of the study. A computer-generated, randomised list was created using a permuted block design. The participants were randomly assigned to one of the three groups (random assignment 1:1:1). These were (a) a standard psychiatric assessment group: patients completed the standard psychiatric assessment; (b) a QoL assessment group: patients completed a QoL questionnaire in addition to the standard psychiatric assessment; and (c) a QoL feedback group: feedback regarding the QoL scores was presented to clinicians in addition to the standard psychiatric assessment. The purpose of the QoL assessment group was to isolate the effect of a single assessment (i.e. without feedback) in the clinical use of QoL. Evaluations were performed at three different time points: (a) at randomisation (baseline; $T_{0}$ ) as well as 3 months $\left(T_{1}\right)$ and 6 months $\left(T_{2}\right)$ after randomisation.

\section{Groups}

Standard psychiatric assessment group

In this group each patient received a standard psychiatric assessment performed by a multidisciplinary team that included a psychiatrist, a clinical psychologist, a nurse and a social worker when appropriate. The standard psychiatric assessment was based on a face-to-face interview, clinical examination and standardised tools (i.e. Positive and Negative Syndrome Scale (PANSS), ${ }^{22,23}$ Calgary Depression Scale for Schizophrenia (CDSS), ${ }^{24,25}$ Extrapyramidal Symptoms Rating Scale (ESRS) ${ }^{26}$ and Global Assessment of Functioning $\left.(\mathrm{GAF})^{27}\right)$. Special attention was given to psychotic and depressive symptoms, drug-induced movement disorders and global functioning. This assessment may therefore play a role in the: (a) assessment of the clinical stability of the patient (for example symptomatic and functional remission); (b) detection and prevention of comorbid somatic and psychiatric disorders; (c) initiation or adaptation of specific pharmacological treatments; (d) evaluation of drug-induced disorders; (e) initiation of psychosocial therapy such as cognitive remediation and psychosocial rehabilitation; and (f) addressing of the administrative and financial issues (e.g. health insurance, free state aid).

\section{QoL assessment group}

In this group patients received a self-administered QoL questionnaire at each evaluation. Patients completed and returned

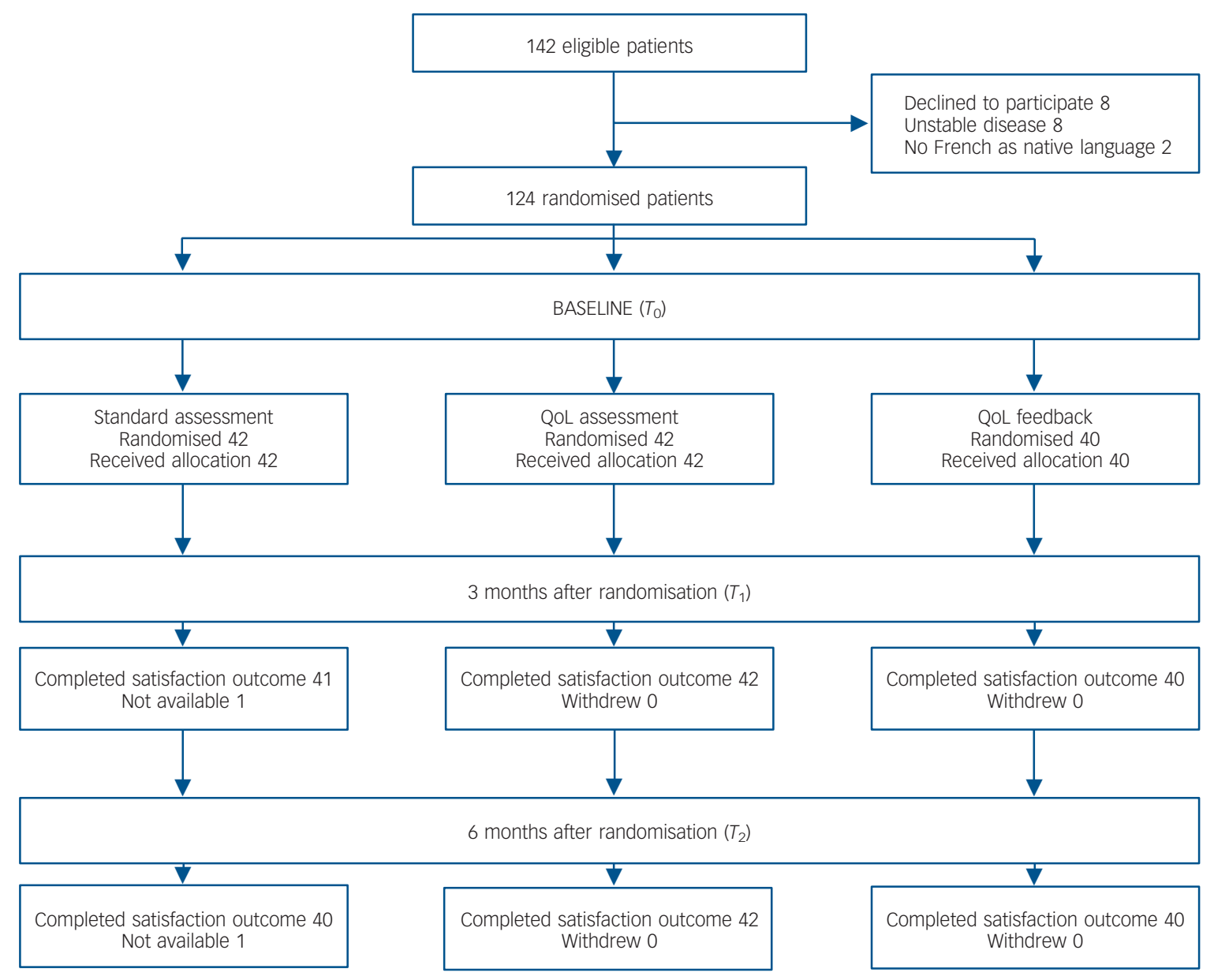

Fig. 1 Flow diagram of participant progress through the phases of the study. 
the questionnaire to a research assistant before the standard psychiatric assessment. The research assistant was independent of the care team, and the QoL scores were not returned to the clinicians. Quality of life was assessed using the S-QoL questionnaire, which is a self-administered questionnaire designed for people with schizophrenia. ${ }^{28}$ The S-QoL is a multidimensional, 41-item instrument that was developed based on patient views, and assesses eight dimensions: psychological well-being, self-esteem, family relationships, relationships with friends, resilience, physical well-being, autonomy, and sentimental life; and a total score. Dimension and index scores range from 0 (low QoL) to 100 (high QoL).

\section{QoL feedback group}

In this group the patient completed and returned the S-QoL questionnaire to the research assistant at each evaluation. The assistant entered the item scores on a computer. A specific algorithm program calculated QoL scores. These scores and the scores of previous evaluations were provided to the care team before the standard psychiatric assessment. In addition, population norms ${ }^{28,29}$ were provided to help clinicians interpret QoL scores. No other advice or guidelines regarding data interpretation and use were provided to clinicians. Patient management was entirely at the discretion of the treating physician.

\section{Evaluation criteria}

\section{Primary criterion}

The primary evaluation criterion was patient satisfaction, which was assessed using three items relating to different satisfaction domains including: global satisfaction; satisfaction/trust with the staff/care; and satisfaction/trust with the care structure. Because no valid French satisfaction questionnaire for out-patients with schizophrenia is available, 'ad hoc' questions were elaborated/ created according to the items of the QSH-45, which is a wellvalidated French in-patient satisfaction questionnaire, ${ }^{30}$ and from our own experience. ${ }^{31}$ Three questions were developed by the steering committee project: (a) What is your degree of satisfaction regarding your global care management?; (b) What is your degree of satisfaction regarding the care structure?; and (c) What is your degree of satisfaction regarding the care staff? The primary criterion was global satisfaction at $T_{2}$, and the other items were considered as secondary criteria. All items were worded positively and assessed using a four-point Likert scale from 1 (very unsatisfied) to 4 (very satisfied). Satisfaction was assessed at $T_{1}$ and $T_{2}$.

\section{Secondary criteria}

We used PANSS to assess psychotic symptomatology. This scale is composed of three subscales: positive, negative and general psychopathology. ${ }^{22,23}$ Higher scores indicate more severe symptomatologies. We used the CDSS to examine depressive symptomatology; it uses a nine-item scale that evaluates depression independent of extrapyramidal and negative symptoms. ${ }^{24,25}$ The CDSS is specifically designed for patients with schizophrenia. Higher scores indicate greater levels of depression. Drug-induced movement disorders (such as Parkinsonism, akathisia, dystonia and dyskinesia) were evaluated using the ESRS. ${ }^{26}$ Higher scores indicate more severe disorders. Global functioning was assessed using GAF. The GAF considers psychological, social and occupational functioning, and scores range from 0 to 100 . Higher scores indicate higher levels of functioning. ${ }^{27}$ Disease severity was assessed using the Clinical Global Impression (CGI) severity scale. The CGI classifies disease severity as mild, moderate or severe. ${ }^{32}$ Psychotic symptomatology, depression, drug-induced movement disorders, global functioning and severity of disease were assessed at $T_{0}, T_{1}$ and $T_{2}$. The psychiatrist indicated any medication changes between $T_{0}$ and $T_{1}$ as well as between $T_{1}$ and $T_{2}$.

\section{Additional data}

The following parameters were recorded for each participant: gender, age, education level $(<12$ years $/ \geqslant 12$ years), living arrangement (partner or parents/alone) and employment status (no/yes).

\section{Statistical analyses}

Baseline characteristics were compared across the three groups. Frequencies were compared using chi-squared tests, and quantitative variables were compared using the Kruskal-Wallis one-way analysis of variance on ranks with a post hoc Dunnett's test. The proportions of patient global satisfaction at $T_{2}$ (primary criterion) were compared across the three groups. Group comparisons with regard to the other scores (i.e. the PANSS positive, negative and general psychopathologies as well as CDSS, ESRS and GAF scores) were performed using analysis of variance. Statistical significance was defined as $P<0.05$. Statistical analyses were performed using SPSS Statistics for Windows, Version 17.0.

\section{Results}

\section{Participants}

Of the 142 patients who were eligible, 124 participants were enrolled: 42 were enrolled in the standard psychiatric assessment group, 42 in the QoL assessment group and 40 in the QoL feedback group. All but two patients in the standard psychiatric assessment group completed the 3- and 6-month assessments (Fig. 1). The mean age of participants was 41.1 years (s.d. =11.8); $67.7 \%$ were male, and $21.8 \%$ had at least 12 years of education. These patients were mildly ill, with a mean total PANSS score of 63.0 (s.d. $=21.6$ ) and positive, negative and general psychopathology subscale scores of 12.9 (s.d.=5.9), 15.6 (s.d.=6.3) and $34.6 \quad($ s.d.=11.5) respectively. Patient characteristics did not differ across the three groups at baseline (Table 1). The proportion of highly satisfied patients in the entire sample ranged from 64.2 to $68.3 \%$ at 3 months and from 61.5 to $65.6 \%$ at 6 months (Table 2).

\section{The effects of QoL assessment and feedback on patient satisfaction}

Global satisfaction and satisfaction/trust with the care structure significantly differed across the three groups at the 6-month follow-up (Table 2): a significantly larger percentage of patients reported high levels of satisfaction in the QoL feedback group compared with the standard psychiatric assessment and QoL assessment groups with regard to these domains. In particular, global satisfaction was significantly higher in the QoL feedback group (72.5\% patients had high levels of satisfaction) compared with the standard psychiatric assessment (67.5\%) and QoL assessment groups $(45.2 \% ; P=0.025)$. This trend towards higher satisfaction in the QoL feedback group was also found at the 3-month follow-up visit with regard to global satisfaction and satisfaction/trust with the staff/care. A total of $75 \%, 68.3 \%$ and $50.0 \%$ of patients in the QoL feedback, standard psychiatric 


\begin{tabular}{|c|c|c|c|c|c|}
\hline & $\begin{array}{c}\text { Total } \\
(n=124)\end{array}$ & $\begin{array}{c}\text { Standard assessment } \\
\text { group } \\
(n=42)\end{array}$ & $\begin{array}{l}\text { QoL } \\
\text { assessment group } \\
(n=42)\end{array}$ & $\begin{array}{l}\text { QoL feedback } \\
\text { group } \\
(n=40)\end{array}$ & $P^{\mathrm{a}}$ \\
\hline \multicolumn{6}{|l|}{ sociodemographic } \\
\hline Age, years: mean (s.d.) & $41.08(11.77)$ & $41.95(12.05)$ & $41.76(13.14)$ & $39.45(9.92)$ & 0.582 \\
\hline \multicolumn{6}{|l|}{ Gender, $n$ (\%) } \\
\hline Men & $84(67.7)$ & $32(76.2)$ & $27(64.3)$ & $25(62.5)$ & \multirow[t]{2}{*}{0.349} \\
\hline Women & $40(32.3)$ & $10(23.8)$ & $15(35.7)$ & $15(37.5)$ & \\
\hline \multicolumn{6}{|l|}{ Educational level, $n$ (\%) } \\
\hline$<12$ years & $97(78.2)$ & $37(88.1)$ & $29(69.0)$ & $31(77.5)$ & \multirow[t]{2}{*}{0.106} \\
\hline$\geqslant 12$ years & $27(21.8)$ & $5(11.9)$ & $13(31.0)$ & $9(22.5)$ & \\
\hline \multicolumn{6}{|l|}{ Partnership status, $n(\%)$} \\
\hline Not single & $69(55.6)$ & $25(59.5)$ & $22(52.4)$ & $22(55)$ & \multirow[t]{2}{*}{0.801} \\
\hline Single & $55(44.4)$ & $17(40.5)$ & $20(47.6)$ & $18(45.0)$ & \\
\hline \multicolumn{6}{|l|}{ Employment status, $n$ (\%) } \\
\hline No & $107(86.3)$ & $37(88.1)$ & $35(83.3)$ & $35(87.5)$ & \multirow[t]{2}{*}{0.788} \\
\hline Yes & $17(13.7)$ & $5(11.9)$ & $7(16.7)$ & $5(12.5)$ & \\
\hline \multicolumn{6}{|l|}{ Clinical } \\
\hline \multicolumn{6}{|l|}{ Positive and Negative Syndrome Scale, mean (s.d.) } \\
\hline Total & $63.01(21.59)$ & $64.74(19.24)$ & $64.19(23.58)$ & $59.87(21.96)$ & 0.445 \\
\hline Positive & $12.90(5.92)$ & $13.33(5.72)$ & $13.36(6.81)$ & $11.95(5.09)$ & 0.530 \\
\hline Negative & $15.56(6.27)$ & $16.33(6.22)$ & $15.50(6.67)$ & $14.79(5.92)$ & 0.395 \\
\hline General psychopathology & 34.55 (11.48) & $35.07(9.87)$ & $35.33(12.20)$ & $33.13(12.44)$ & 0.445 \\
\hline Calgary Depression Scale for Schizophrenia, mean (s.d.) & $4.47(3.57)$ & $4.90(3.84)$ & $4.4(3.231)$ & $4.05(3.65)$ & 0.604 \\
\hline \multicolumn{6}{|l|}{ Extrapyramidal Symptoms Rating Scale, mean (s.d.) } \\
\hline Dyskinesia & $0.09(0.38)$ & $0.19(0.59)$ & $0.05(0.22)$ & $0.03(0.16)$ & 0.183 \\
\hline Parkinsonism & $0.12(0.54)$ & $0.21(0.81)$ & $0.10(0.37)$ & $0.05(0.22)$ & 0.495 \\
\hline Dystonia & $0.06(0.23)$ & $0.07(0.26)$ & $0.07(0.26)$ & $0.03(0.16)$ & 0.580 \\
\hline Akathisia & $0.07(0.34)$ & $0.14(0.47)$ & $0.07(0.34)$ & $0(0)$ & 0.135 \\
\hline Global Assessment of Functioning, mean (s.d.) & $61.94(13.18)$ & $60.9(13.67)$ & $61.57(12.36)$ & $63.43(13.66)$ & 0.604 \\
\hline Clinical Global Impression of Severity, $n(\%)$ & & & & & 0.678 \\
\hline Mild & $39(31.5)$ & $12(28.6)$ & $12(28.6)$ & $15(37.5)$ & \\
\hline Moderate & $68(54.8)$ & $23(54.8)$ & $26(61.9)$ & $19(47.5)$ & \\
\hline Severe & $17(13.7)$ & $7(16.7)$ & $4(9.5)$ & $6(15.0)$ & \\
\hline
\end{tabular}

\begin{tabular}{|c|c|c|c|c|c|}
\hline & \multicolumn{4}{|c|}{$n(\%)$} & \multirow[b]{2}{*}{$P^{a}$} \\
\hline & $\begin{array}{c}\text { Total } \\
(n=124)\end{array}$ & $\begin{array}{l}\text { Standard } \\
\text { assessment } \\
\text { group }\end{array}$ & $\begin{array}{l}\text { QoL assessment } \\
\text { group } \\
(n=42)\end{array}$ & $\begin{array}{l}\text { QoL feedback } \\
\text { group } \\
(n=40)\end{array}$ & \\
\hline \multicolumn{6}{|l|}{$T_{1}$ (3 months) } \\
\hline$n$ & 123 & 41 & 42 & 40 & \\
\hline Global satisfaction & & & & & 0.049 \\
\hline From unsatisfied to mild satisfied & $44(35.8)$ & $13(31.7)$ & $21(50.0)$ & $10(25.0)$ & \\
\hline Very satisfied & 79 (64.2) & $28(68.3)$ & $21(50.0)$ & $30(75.0)$ & \\
\hline Satisfaction with staff/care & & & & & 0.029 \\
\hline From unsatisfied to mild satisfied & $41(33.3)$ & $13(31.7)$ & $20(47.6)$ & $8(20.0)$ & \\
\hline Very satisfied & $82(66.7)$ & $28(68.3)$ & $22(52.4)$ & $32(80.0)$ & \\
\hline Satisfaction with the care structure & & & & & 0.153 \\
\hline From unsatisfied to mild satisfied & $39(31.7)$ & $10(24.4)$ & $18(42.9)$ & $11(27.5)$ & \\
\hline Very satisfied & $84(68.3)$ & $31(75.6)$ & $24(57.1)$ & $29(72.5)$ & \\
\hline \multicolumn{6}{|l|}{$T_{2}$ (6 months) } \\
\hline$n$ & 122 & 40 & 42 & 40 & \\
\hline Global satisfaction & & & & & 0.025 \\
\hline From unsatisfied to mild satisfied & 47 (38.5) & $13(32.5)$ & $23(54.8)$ & $11(27.5)$ & \\
\hline Very satisfied & $75(61.5)$ & $27(67.5)$ & $19(45.2)$ & $29(72.5)$ & \\
\hline Satisfaction with staff/care & & & & & 0.095 \\
\hline From unsatisfied to mild satisfied & $42(34.4)$ & $14(35.0)$ & $19(45.2)$ & $9(22.5)$ & \\
\hline Very satisfied & $80(65.6)$ & $26(65.0)$ & $23(54.8)$ & $31(77.5)$ & \\
\hline Satisfaction with the care structure & & & & & 0.025 \\
\hline From unsatisfied to mild satisfied & $42(34.4)$ & $12(30.0)$ & $21(50.0)$ & $9(22.5)$ & \\
\hline Very satisfied & $80(65.6)$ & $28(70.0)$ & $21(50.0)$ & $31(77.5)$ & \\
\hline
\end{tabular}




\begin{tabular}{|c|c|c|c|c|c|}
\hline & $\begin{array}{c}\text { Total } \\
(n=124)\end{array}$ & $\begin{array}{l}\text { Standard assessment } \\
\text { group } \\
(n=42)\end{array}$ & $\begin{array}{l}\text { QoL } \\
\text { assessment group } \\
(n=42)\end{array}$ & $\begin{array}{l}\text { QoL feedback } \\
\text { group } \\
(n=40)\end{array}$ & $P^{a}$ \\
\hline \multicolumn{6}{|l|}{ Positive and Negative Syndrome Scale, mean (s.d.) } \\
\hline Total & $61.20(20.53)$ & $64.64(20.20)$ & $60.55(20.58)$ & $58.28(20.81)$ & 0.227 \\
\hline Positive & $12.48(5.48)$ & $13.47(5.79)$ & $12.36(5.64)$ & $11.58(4.91)$ & 0.223 \\
\hline Negative & $15.21(5.94)$ & $16.07(5.94)$ & $15.07(5.88)$ & $14.45(6.03)$ & 0.358 \\
\hline General psychopathology & $33.51(10.65)$ & $35.10(10.30)$ & $33.12(10.67)$ & $32.25(11.05)$ & 0.312 \\
\hline Calgary Depression Scale for Schizophrenia, mean (s.d.) & $3.63(2.90)$ & $4.19(3.00)$ & $3.5(2.73)$ & $3.18(2.97)$ & 0.229 \\
\hline \multicolumn{6}{|l|}{ Extrapyramidal Symptoms Rating Scale, mean (s.d.) } \\
\hline Dyskinesia & $0.07(0.34)$ & $0.14(0.52)$ & $0.05(0.22)$ & $0.03(0.16)$ & 0.364 \\
\hline Parkinsonism & $0.13(0.54)$ & $0.24(0.82)$ & $0.1(0.37)$ & $0.05(0.22)$ & 0.299 \\
\hline Dystonia & $0.05(0.22)$ & $0.07(0.26)$ & $0.05(0.22)$ & $0.03(0.16)$ & 0.621 \\
\hline Akathisia & $0.08(0.35)$ & $0.14(0.47)$ & $0.07(0.34)$ & $0.03(0.16)$ & 0.364 \\
\hline Global Assessment of Functioning, mean (s.d.) & $64.57(12.97)$ & $62.36(13.33)$ & $65.12(12.12)$ & $66.33(13.43)$ & 0.273 \\
\hline Clinical Global Impression of Severity, $n(\%)$ & & & & & 0.938 \\
\hline Mild & $36(29.0)$ & $11(26.2)$ & $12(28.6)$ & $13(32.5)$ & \\
\hline Moderate & $74(59.7)$ & 25 (59.5) & $26(61.9)$ & $23(57.5)$ & \\
\hline Severe & $14(11.3)$ & $6(14.3)$ & $4(9.5)$ & $4(10.0)$ & \\
\hline Medication change, $n(\%)^{b}$ & & & & & 0.374 \\
\hline Yes & 15 (12.4) & $5(11.9)$ & $3(7.5)$ & 7 (17.9) & \\
\hline No & $106(87.6)$ & 37 (88.1) & 37 (92.5) & 32 (82.1) & \\
\hline
\end{tabular}

assessment and QoL assessment groups, respectively, reported high levels of global satisfaction $(P=0.049)$.

No significant group effect was observed with regard to the different clinical outcomes and changes in medication at the 3-month (data not shown) and 6-month follow-up visits (Table 3). Importantly, there was a trend towards better clinical outcomes (PANSS, CDSS, ESRS, GAF and CGI scores) in the QoL feedback group that was present at 3 months and continued at 6 months. Although not significant, there were more changes made to medication in the QoL feedback group.

\section{Discussion}

This randomised study is the first to provide an evidence base for the routine clinical use of QoL assessment and feedback in the management of patients with schizophrenia. Of particular interest is the finding that patient satisfaction levels were higher when clinicians were provided with QoL assessments compared with that of patients whose clinicians did not have this information. This finding is consistent with previous oncology studies reporting that feedback of QoL scores to clinicians improves patient-physician communication. ${ }^{14-17}$ Quality of life measures may help to understand the subjective experiences that are key in treating people with mental disorders ${ }^{33}$ and improve patientclinician communication. Moreover, better communication is related to decreases in the paternalistic view of care as well as increases in interactive approaches with patients and patient decision-making, all of which lead to increased patient satisfaction. ${ }^{34,35}$ We thus hypothesise that QoL assessment with feedback may provide useful information to psychiatrists, which leads to better clinician-patient communication ${ }^{17}$ and clinician awareness/detection of patients' social and psychological problems, ${ }^{4}$ and that this plays a part in enhancing satisfaction. In addition, our findings provide strong support for integrating QoL assessment and feedback with standard psychiatric assessments. In fact, patient satisfaction predicts future behaviours including adherence with treatment, intent to return for care ${ }^{36-38}$ and final health outcomes. ${ }^{39}$ Thus far, obtaining QoL data in an efficient, real-time manner was difficult and rare in clinical practice. ${ }^{6,10}$ Priority should be given to strategies to implement QoL measurements in routine practice, including providing systematic feedback for clinicians. The logistics of obtaining patient QoL data should be the same as those for other clinical indicators. ${ }^{6,40}$ Interestingly, recent technologies such as electronic medical records are being implemented in psychiatric settings; ${ }^{41-43}$ these methods may efficiently and automatically collect QoL data. ${ }^{10,44,45}$

Despite the positive effect that QoL assessment with feedback had on patient satisfaction (i.e. there was a trend towards improved clinical outcomes in the QoL feedback group), there was no significant effect on other health outcomes (PANSS, CDSS, ESRS, GAF and CGI scores) or patient management (changes in medication). The failure to detect significant between-group differences may be because of the small sample size of each group. Alternatively, this failure might be because the disease severity of our sample tended to be mild, which left little room for health status improvements, especially given the relatively short 6-month follow-up period of our study. ${ }^{46}$ However, these findings are consistent with previous studies that have failed to report any changes in clinical management or health outcomes. ${ }^{13,47}$ Therefore, we cannot exclude the possibility that clinicians did not optimally use the QoL feedback. In particular, studies have suggested that clinicians did not feel comfortable interpreting QoL data to improve QoL of patients. ${ }^{6,40}$ Strategies for the implementation of QoL measurements should include training sessions aimed at motivating professionals to use QoL data and provide norms, advice and guidelines regarding data interpretation and patient management. ${ }^{13}$

One last finding was particularly important in our study. Quality of life assessments without feedback for clinicians was associated with lower patient satisfaction levels compared with patients whose clinicians were provided with QoL feedback and those whose QoL was not assessed. This finding suggests a QoL-assessment nocebo effect (i.e. negative expectations that derived from the clinical encounter and led to poor therapy 
adherence and health outcomes ${ }^{48}$ ). Measuring QoL may cause 'side-effects' through the exploration of sensitive subjects, thereby generating new expectations from clinicians on the part of the patients. ${ }^{49}$ The absence of the appropriate clinical use of these QoL data (i.e. examine, interpret and act) might negatively affect patient satisfaction (i.e. create a match or mismatch between patient expectations and perceptions ${ }^{24}$ ). Thus, this finding has direct implications for both research and clinical practice. Clinicians should consider possible nocebo effects.

\section{Limitations and perspectives}

Certain limitations of this study must be considered carefully. First, the sample might not be representative of the entire population of patients with schizophrenia. The participants had paranoid schizophrenia, and were mostly male, middle aged, with mild disease severity and more than 5 years of illness duration. Likewise, the clinicians might not be representative of all of their colleagues in the mental healthcare system because the study was conducted at one university hospital. Therefore, replication is needed in other settings using more diverse and larger groups of patients and clinicians.

Second, clinicians treated patients from all three study groups; this design may have contaminated the results. Therefore, the differences between each group may be underestimated. Future studies should better control for contamination effects, especially by using a randomised cluster design. ${ }^{13}$

Third, a longer follow-up period is necessary to better explore the impact of QoL assessment and feedback on clinical outcomes and changes in patient management ${ }^{13}$ as well as to confirm the trend towards improved clinical outcomes in the QoL feedback group. Studying the effect of measuring QoL on other relevant outcomes such as social variables (i.e. how patients live, function in society and perform various roles) ${ }^{50}$ or recovery (i.e. subjective changes in how people appraise their lives and the extent to which they view themselves as meaningful agents in the world) would be necessary to evaluate long-term outcomes. ${ }^{51,52}$

Fourth, our approach for measuring satisfaction, which was not based on a validated questionnaire but rather on three ad hoc questions, is debatable. At the beginning of the project, no validated questionnaire assessing patient satisfaction in psychiatry was available in French. However, it can be assumed that the choice of the three questions was both reasonable and pragmatic. The three items were: (a) developed from a standardised and wellvalidated questionnaire of patients' satisfaction with care; ${ }^{24,53,54}$ (b) identified as relevant both from an extensive review of the literature on this topic ${ }^{25}$ and by the steering committee of this project; and (c) in accordance with current standards in terms of content and response modalities. ${ }^{41,55}$ The measurement bias can be considered to be minimal.

Finally, our findings concern only patients with schizophrenia and might not be generalisable to all mental disorders and chronic diseases. The current findings need to be replicated in future studies that include other chronic diseases.

\section{Implications}

Our study indicates that QoL assessment with feedback for clinicians has a positive impact on patient's satisfaction. This finding confirms the relevance of including QoL in clinical practice. However, the absence of a significant effect of QoL assessment with feedback on clinical outcomes suggests that clinicians did not optimally use these data. In addition to feedback, providing advice and guidelines regarding data interpretation and use is necessary to ensure that QoL data have direct implications for clinical practice. Finally, our findings suggest a nocebo effect of QoL assessment without feedback that clinicians should consider.

\footnotetext{
Laurent Boyer, MD, PhD, Aix-Marseille University, EA 3279 - Public Health, Chronic Diseases and Quality of Life - Research Unit, Marseille; Christophe Lançon MD, PhD, Aix-Marseille University, EA 3279 - Public Health, Chronic Diseases and Quality of Life - Research Unit and Department of Psychiatry, Sainte-Marguerite University Hospital, Marseille; Karine Baumstarck, MD, PhD, Aix-Marseille University, EA 3279 - Public Health, Chronic Diseases and Quality of Life - Research Unit, Marseille; Nathalie Parola, PhD, Department of Psychiatry, Sainte-Marguerite University Hospital, Marseille; Julie Berbis, MD, Pascal Auquier, MD, PhD, Aix-Marseille University, EA 3279 - Public Health, Chronic Diseases and Quality of Life - Research Unit, Marseille, France

Correspondence: Laurent Boyer, MD, PhD, EA 3279 - Self-Perceived Health Assessment Research Unit, School of Medicine, La Timone University, 13005 Marseille, France. Email: laurent.boyer@ap-hm.fr

First received 7 Nov 2012, final revision 13 Mar 2013, accepted 27 Mar 2013
}

\section{Funding}

This work was supported by institutional grants from the 2005 Programme Hospitalier Recherche Clinique National. The sponsor was the Assistance Publique, Hôpitaux de Marseille, France; and its role was to control the appropriateness of ethical and legal considerations.

\section{Acknowledgements}

The authors are grateful to all the patients for their participation in the study. The authors thank the clinicians who identified potential participants for the trial, Dr Marie-Claude Simeoni for her technical assistance, Elodie Guilhot for her contribution for the statistical analyses, Therese Vigne for the data entry.

\section{References}

1 Hofer A, Baumgartner S, Bodner T, Edlinger M, Hummer M, Kemmler G, et al. Patient outcomes in schizophrenia II: the impact of cognition. Eur Psychiatry 2005; 20: 395-402.

2 Hofer A, Baumgartner S, Edlinger M, Hummer M, Kemmler G, Rettenbacher MA, et al. Patient outcomes in schizophrenia I: correlates with sociodemographic variables, psychopathology, and side effects. Eur Psychiatry 2005; 20: 386-94.

3 Nelson EC, Landgraf JM, Hays RD, Wasson JH, Kirk JW. The functional status of patients. How can it be measured in physicians' offices? Med Care 1990; 28: 1111-26.

4 Sprangers MA, Aaronson NK. The role of health care providers and significant others in evaluating the quality of life of patients with chronic disease: a review. J Clin Epidemiol 1992; 45: 743-60.

5 Awad AG, Voruganti LN. Measuring quality of life in patients with schizophrenia: an update. Pharmacoeconomics 2012; 30: 183-95.

6 Halyard MY, Frost MH, Dueck A, Sloan JA. Is the use of QOL data really any different than other medical testing? Curr Probl Cancer 2006; 30: 261-71.

7 Greenhalgh J, Long AF, Flynn R. The use of patient reported outcome measures in routine clinical practice: lack of impact or lack of theory? Soc Sci Med 2005; 60: 833-43.

8 Gilbody SM, House AO, Sheldon TA. Psychiatrists in the UK do not use outcomes measures. National survey. Br J Psychiatry 2002; 180: 101-3.

9 Boyer L, Auquier P. The lack of impact of quality-of-life measures in schizophrenia: a shared responsibility? Pharmacoeconomics 2012; 30 : $531-2$.

10 Gutteling JJ, Busschbach JJ, de Man RA, Darlington AS. Logistic feasibility of health related quality of life measurement in clinical practice: results of a prospective study in a large population of chronic liver patients. Health Qual Life Outcomes 2008; 6: 97.

11 Morris J, Perez D, McNoe B. The use of quality of life data in clinical practice. Qual Life Res 1998; 7: 85-91.

12 Gilbody SM, House AO, Sheldon T. Routine administration of Health Related Quality of Life (HRQOL) and needs assessment instruments to improve psychological outcome - a systematic review. Psychol Med 2002; 32: 1345-56. 
13 Luckett T, Butow PN, King MT. Improving patient outcomes through the routine use of patient-reported data in cancer clinics: future directions. Psychooncology 2009; 18: 1129-38.

14 Takeuchi EE, Keding A, Awad N, Hofmann U, Campbell LJ, Selby PJ, et al. Impact of patient-reported outcomes in oncology: a longitudinal analysis of patient-physician communication. J Clin Oncol 2011; 29: 2910-7.

15 Velikova G, Booth L, Smith AB, Brown PM, Lynch P, Brown JM, et al. Measuring quality of life in routine oncology practice improves communication and patient well-being: a randomized controlled trial. J Clin Oncol 2004; 22: 714-24.

16 Taenzer P, Bultz BD, Carlson LE, Speca M, DeGagne T, Olson K, et al. Impact of computerized quality of life screening on physician behaviour and patient satisfaction in lung cancer outpatients. Psychooncology 2000; 9: $203-13$.

17 Detmar SB, Muller MJ, Schornagel JH, Wever LD, Aaronson NK. Health-related quality-of-life assessments and patient-physician communication: a randomized controlled trial. JAMA 2002; 288 3027-34.

18 Knaup C, Koesters M, Schoefer D, Becker T, Puschner B. Effect of feedback of treatment outcome in specialist mental healthcare: meta-analysis. Br J Psychiatry 2009; 195: 15-22.

19 Slade $M$, Mccrone $P$, Kuipers E, Leese $M$, Cahill S, Parabiaghi A, et al. Use of standardised outcome measures in adult mental health services. Randomised controlled trial. Br J Psychiatry 2006; 189: 330-6.

20 American Psychiatric Association. Diagnostic and Statistical Manual of Mental Disorders (4th edn), text revision (DSM-IV-TR). APA, 2000.

21 Jeste DV, Palmer BW, Appelbaum PS, Golshan S, Glorioso D, Dunn LB, et al. A new brief instrument for assessing decisional capacity for clinical research. Arch Gen Psychiatry 2007; 64: 966-74.

22 Kay SR, Opler LA, Fiszbein A. Significance of positive and negative syndromes in chronic schizophrenia. Br J Psychiatry 1986; 149: 439-48.

23 Lancon C, Reine G, Llorca PM, Auquier P. Validity and reliability of the French-language version of the Positive and Negative Syndrome Scale (PANSS). Acta Psychiatr Scand 1999; 100: 237-43.

24 Addington D, Addington J, Maticka-Tyndale E. Assessing depression in schizophrenia: the Calgary Depression Scale. Br J Psychiatry 1993; 162 (suppl 22): 39-44.

25 Lancon C, Auquier P, Reine G, Toumi M, Addington D. Evaluation of depression in schizophrenia: psychometric properties of a French version of the Calgary Depression Scale. Psychiatry Res 1999; 89: 123-32.

26 Chouinard G, Margolese HC. Manual for the Extrapyramidal Symptom Rating Scale (ESRS). Schizophr Res 2005; 76: 247-65.

27 Endicott J, Spitzer RL, Fleiss JL, Cohen J. The global assessment scale. A procedure for measuring overall severity of psychiatric disturbance. Arch Gen Psychiatry 1976; 33: 766-71.

28 Auquier P, Simeoni MC, Sapin C, Reine G, Aghababian V, Cramer J, et al. Development and validation of a patient-based health-related quality of life questionnaire in schizophrenia: the S-QoL. Schizophr Res 2003; 63: 137-49.

29 Boyer L, Simeoni MC, Loundou A, D'Amato T, Reine G, Lancon C, et al. The development of the S-QoL 18: a shortened quality of life questionnaire for patients with schizophrenia. Schizophr Res 2010; 121: 241-50.

30 Antoniotti S, Baumstarck-Barrau K, Simeoni MC, Sapin C, Labarere J, Gerbaud L, et al. Validation of a French hospitalized patients' satisfaction questionnaire: the QSH-45. Int J Qual Health Care 2009; 21: 243-52.

31 Boyer L, Baumstarck-Barrau K, Cano N, Zendjidjian X, Belzeaux R, Limousin S, et al. Assessment of psychiatric inpatient satisfaction: a systematic review of self-reported instruments. Eur Psychiatry 2009; 24: 540-9.

32 Guy W. ECDEU Assessment Manual for Psychopharmacology. US Department of Health and Human Services, 1976.

33 Yang S, Mulvey EP, Falissard B. Textual data in psychiatry: reasoning by analogy to quantitative principles. J Nerv Ment Dis 2012; 200: 668-75.
34 Thind A, Maly R. The surgeon-patient interaction in older women with breast cancer: what are the determinants of a helpful discussion? Ann Surg Oncol 2006; 13: 788-93.

35 Nordon C, Rouillon F, Barry C, Gasquet I, Falissard B. Determinants of treatment satisfaction of schizophrenia patients: results from the ESPASS study. Schizophr Res 2012; 139: 211-7.

36 Cleary PD, McNeil BJ. Patient satisfaction as an indicator of quality care. Inquiry 1988; 25: 25-36.

37 Fitzpatrick R. Surveys of patients satisfaction: I - Important general considerations. BMJ 1991; 302: 887-9.

38 Ware Jr JE, Davies AR. Behavioral consequences of consumer dissatisfaction with medical care. Eval Program Plann 1983; 6: 291-7.

39 Chue $P$. The relationship between patient satisfaction and treatment outcomes in schizophrenia. J Psychopharmacol 2006; 20 (suppl 6): 38-56.

40 Halyard MY, Frost MH, Dueck A. Integrating QOL assessments for clinical and research purposes. Curr Probl Cancer 2006; 30: 319-30.

41 Boyer L, Baumstarck-Barrau K, Belzeaux R, Azorin JM, Chabannes JM, Dassa $D$, et al. Validation of a professionals' satisfaction questionnaire with electronic medical records (PSQ-EMR) in psychiatry. Eur Psychiatry 2011; 26: 78-84.

42 Boyer L, Renaud MH, Baumstarck-Barrau K, Fieschi M, Samuelian JC. Establishment of an electronic medical record in a psychiatric hospital: evolution of professionals' perceptions. Encephale 2010; 36: 236-41.

43 Boyer L, Renaud MH, Limousin S, Henry JM, Caietta P, Fieschi M, et al. Perception and use of an electronic medical record system by professionals of a public psychiatric hospital. Encephale 2009; 35: 454-60.

44 Wright EP, Selby PJ, Crawford M, Gillibrand A, Johnston C, Perren TJ, et al. Feasibility and compliance of automated measurement of quality of life in oncology practice. J Clin Oncol 2003; 21: 374-82.

45 Velikova G, Wright EP, Smith AB, Cull A, Gould A, Forman D, et al. Automated collection of quality-of-life data: a comparison of paper and computer touch-screen questionnaires. J Clin Oncol 1999; 17: 998-1007.

46 Hodgson R, Bushe C, Hunter R. Measurement of long-term outcomes in observational and randomised controlled trials. Br J Psychiatry 2007; 191 (suppl 50): s78-84

47 Rosenbloom SK, Victorson DE, Hahn EA, Peterman AH, Cella D. Assessment is not enough: a randomized controlled trial of the effects of HRQL assessment on quality of life and satisfaction in oncology clinical practice. Psychooncology 2007; 16: 1069-79.

48 Colloca L, Finniss D. Nocebo effects, patient-clinician communication, and therapeutic outcomes. JAMA 2012; 307: 567-8.

49 Higginson IJ, Carr AJ. Measuring quality of life: using quality of life measures in the clinical setting. BMJ 2001; 322: 1297-300.

50 Priebe S. Social outcomes in schizophrenia. Br J Psychiatry 2007; 191 (suppl 50): s15-20.

51 Lysaker PH, Glynn SM, Wilkniss SM, Silverstein SM. Psychotherapy and recovery from schizophrenia: a review of potential applications and need for future study. Psychol Serv 2010; 7: 75-91.

52 Roe D, Mashiach-Eizenberg M, Lysaker PH. The relation between objective and subjective domains of recovery among persons with schizophreniarelated disorders. Schizophr Res 2011; 131: 133-8.

53 Barlesi F, Barrau K, Loundou A, Doddoli C, Simeoni MC, Auquier P, et al. Impact of information on quality of life and satisfaction of non-small cell lung cancer patients: a randomized study of standardized versus individualized information before thoracic surgery. J Thorac Oncol 2008; 3: 1146-52.

54 Barlesi F, Boyer L, Doddoli C, Antoniotti S, Thomas P, Auquier P. The place of patient satisfaction in quality assessment of lung cancer thoracic surgery. Chest 2005; 128: 3475-81.

55 Crocker L, Algina J. Introduction to Classical and Modern Test Theory. Holt, Rinehart and Winston, 1986. 